\title{
Assessment of Incineration Process Performance in a District Hospital Using Statistical Analysis
}

\author{
Samwel Victor Manyele, Ignatio Simon Kagonji \\ Department of Chemical and Mining Engineering, Collage of Engineering and Technology, \\ University of Dar es Salaam, Dar es Salaam, Tanzania \\ Email: smanyele@udsm.ac.tz,kagonji@yahoo.com
}

Received June 5, 2012; revised July 10, 2012; accepted July 20, 2012

\begin{abstract}
The objective of this study was to assess the performance of an old existing medical waste incinerator in a district (Temeke) hospital. The medical waste incinerated was grouped into two categories: sharps waste and other waste. The parameters assessed included amounts of sharps and other waste incinerated, amount of fuel used and the incineration cycle time. One incineration cycle was conducted per day and data was collected for 22 months $(N=653)$. It was established that the total waste incinerated per day ranged from 70 to $120 \mathrm{~kg}$, completing the process between 2 and 4 hrs and consuming 20 to $40 \mathrm{~L}$ of fuel per day. The analysis showed further that sharps waste incinerated were $25 \%$ of the total waste while other waste incinerated were about $75 \%$ on average. The average diesel oil used was $30 \mathrm{~L} /$ day and average cycle time was observed to be $3 \mathrm{hrs}$, both being excessively high indicating that the performance of the incinerator was poor. The statistical analysis was used to reveal stronger variations in other waste than sharps waste. The PDF plots, skewness and kurtosis values indicated that there were weak variations in the daily diesel oil consumed and incineration cycle time while stronger variations were observed in the other waste compared to sharps waste data. Normalization of the incinerator performance data allowed comparison between different data types also indicating poor performance of the incinerator. Proper segregation at point of generation and proper storage of medical waste was recommended. It was further recommended for the hospital to install a new and efficient incinerator with short incineration cycle time and less fuel consumption.
\end{abstract}

Keywords: Incinerator Performance; Medical Waste Incineration; Fuel Consumption; Incineration Cycle Time; Sharps Waste; Statistical Analysis

\section{Introduction}

Hospitals are experiencing problems of high fuel consumption and longer incineration cycle times, using old incinerator designs. Moreover, incinerator emissions and ash handling problems are evident especially where incinerators are poorly performing. This situation can cause diseases such as cancer, pulmonary infections, heart diseases, etc., to the health workers and societies around hospitals. The main source of hazards in the incineration process is presence of toxic and hazardous chemical compounds from poorly operated incinerators. Other problems facing the hospitals include excessive fuel consumption, extended incineration cycle times, air pollution (from toxic gases and particulate matter), soil and ground-water pollution due to poor ash disposal methods. Thus, it is important to ensure that the design, operation, testing, and maintenance of incineration process provide maximum safety and minimum risk to the environment. Therefore, the need for conducting incinerator assessment is of vital importance. The parameters studied in this work included the amounts of sharps waste and other waste incinerated in relation to amount of diesel oil used in the process and time taken to complete the entire incineration cycle. This leads to increased expenses in the operations of any district hospital.

This paper gives more insight on the incineration process, and its major challenges. The study was conducted at Temeke district hospital for 22 months consecutively covering 653 days of daily data collection. Medical wastes incinerated were segregated in two categories: sharps waste containing needles, syringe and surgical blades [1]. Other waste category included all waste such as pathological waste (human tissues, organs and body fluid), pharmaceutical waste (drugs, vaccines spoiled or expired), and chemical waste (detergents, dressing solutions), grouped together $[2,3]$.

\section{Literature Review}

\subsection{Medical Waste Incineration}

Incineration is the waste treatment technology that in- 
volves thermal destruction of medical waste at higher temperature, usually $850^{\circ} \mathrm{C}-1000^{\circ} \mathrm{C}$. Incineration of waste materials converts the waste into bottom ash, flue gases, particulates and heat which can in turn be used to generate electric power. The flue gases are usually cleaned of pollutants before they are dispersed in the atmosphere [4-6]. Modern incineration systems use high temperatures, controlled air supply, and excellent mixing to change the chemical, physical, or biological character or composition of waste materials. The new systems are equipped with state-of-the-art air pollution control devices to capture particulate and acidic gaseous emission like wet scrubbers (Manyele, 2008).

Preliminary studies have shown that incineration is still the suitable method of decontaminating the medical waste in Tanzanian hospitals [7]. It is also the most often used method in developed countries as well (Switzerland, German, Sweden, USA, and Canada). The major advantages of incineration include volume reduction (by more than 90\%), assured destruction (99\% and above), high sterilization efficiency, high weight reduction, and the ability to manage most types of wastes with little processing before treatment [2,7-9]. However, incineration is facing political challenges when emissions are not controlled and also because it is related to mostly publically owned institutions, such that the public feels to have a say on medical waste incineration even when they lack full knowledge.

\subsection{Medical Waste Incineration Process}

The medical waste treatment facilities require several units combined together facilitating different tasks and the overall performance depends on the efficiency of each of these units. The major units include: waste storage unit, waste preparation and feeding, waste combustion unit, flue gas treatment and ash handling. To achieve a high degree of combustion in the combustion chamber, for instance, it is necessary to ensure an adequate combustion temperature, sufficient excess supply of air, an ample mixing of the air with the thermal decomposition gas, and an adequate reaction time. In a successful incinerator design, careful consideration is given to the provision of adequate excess air by use of blowers and the appropriate location of the air supplies. Moreover, the combustion temperature is carefully controlled; the gas flow velocities through the combustion chamber are adequately low; and the gas and solid waste residence times in the combustion chamber are of sufficient duration [10].

Some incinerator designs attempt to accomplish combustion of both the gaseous and solid phases in one combustion chamber. It appears much more preferable, however, to employ two combustion chambers connected in series. In such designs, the waste feed is loaded into the primary chamber where it undergoes thermal decomposition and where the carbon residue burnout is also (later) completed. This is followed by a secondary combustion chamber (afterburner) for oxidizing the remaining gases and volatiles, including the particulate matter carried over from the primary chamber, under conditions where there is excess air. A support burner and additional air injection equipment are usually required in the secondary chamber to maintain a sufficiently high and consistent temperature [11]. The excess air incinerators allow an excess of oxygen during the primary combustion process so that both the gaseous and solid fractions can burn directly in one combustion chamber. The controlled air incinerators limit the air supply in the primary combustion step to near or below the stoichiometric ratio, and a secondary combustion step is needed for completion of the combustion of gaseous fraction in an oxygen rich atmosphere [12].

The pyrolyzing incinerators employ secondary chambers where the ash and the gaseous products of pyrolysis are fully oxidized in an oxygen rich atmosphere. The incinerators employed to produce the slag use relatively high process temperatures to burn the carbonaceous residue by receiving heat, typically from burning fuel, thus releasing an amount of heat energy sufficient to convert all non-combustibles contained in the waste feed to molten slag. The combustion of both the solid and gaseous fractions of the waste is accomplished in one chamber and the fly ash resulting from the process leaves the chamber with the off-gas. The composition and character of the ash vary with the combustion technique used and with the composition of the waste feed. The excess air and the controlled air incineration leave a similar end product but contain less carbon [13].

\subsection{Average Waste Incineration Rate}

The average waste incineration rate per year for an incinerator studied is about 35 tons which is very low compared to waste generation capacity for a district hospital located in urban areas. It is estimated that the total amount of hospital waste incinerated, including the waste incinerated off-site, to be about 80 percent of the total hospital waste in the United States [12]. In 2001 the United States had 190 operating incinerators with a design capacity of 114,339 tons/day and an annual capacity of 35.5 million tons. Germany, which has the highest concentration of incinerators in Europe, has 530 units with an annual capacity of 107 million tons [14].

Incineration can be adapted to the destruction of a wide variety of wastes. This includes municipal solid wastes, industrial wastes, medical wastes, sewage, surface polluted soils and liquids, and the hazardous wastes 
(liquids, tars, sludge's, solids, and vent fumes) generated by industry [15]. Unlike many other methods of waste treatment, incineration is a permanent solution. The major benefit of incineration is that the process actually destroys most of the waste rather than just disposing of or storing it. Many health facilities which were built after World War II in Europe, selected incineration as the method of medical waste disposal over landfills. There was a lack of consideration of exhaust emissions from these units in the original designs, such that, tall stacks were used for dispersion rather than proper air pollution controls. The combustion furnaces were operated at high excess air levels resulting in lower temperatures, incomeplete combustion and high levels of carbon monoxide and unburned hydrocarbons. Typical conditions surrounding these facilities were high soot and odor levels as well as corrosion from acid gas deposition. Poorly designed and ill operated incinerators led to an unhealthy and unsafe environment for the health facilities and neighbors [16].

\subsection{Incinerator Siting, Planning and Quality Control}

Variations in medical waste incineration processes and other innovative technologies continue to appear. At present, controlled air incinerators are popular due to their relatively low (capital, operating and maintenance) cost and their ability to meet existing air standards without air pollution controls [17]. The location of an incinerator can significantly affect dispersion of the plume from the chimney, which in turn affects ambient pollutants concentrations, deposition and exposures of workers and the community to the gaseous emissions. Best practices of siting incinerators have the goal of finding a location that minimizes potential risks to the public health and the environment [2]. Adequate plans, drawings, and quality control are necessary to construct incinerators. Dimensional drawings, tolerances, material lists, etc., are necessary. A lack of adequate quality control in the construction phase results in incorrectly-built facilities, whereby shelters, protective enclosures, and pits have not been constructed in most sites [18].

\subsection{Combustion Temperature and Cycle Time}

Proper design and operation of incinerators should achieve desired temperatures, residence times, and other conditions necessary to destroy pathogens, minimize emissions, avoid clinker formation and slugging of the ash (in the primary chamber), avoid refractory damage and minimize fuel consumption. Good combustion practice (GCP) should be followed to control dioxin and furan emissions [5]. A minimum residence time of one second in the combustion zone at the minimum combus- tion temperature specified in the design is generally considered adequate to provide high-efficiency incineration. The residence time is calculated from the point where most of the combustion has been completed and the incineration temperature has been fully developed. In multichamber incinerators, the residence time is calculated from the secondary burner(s) flame front. If air is introduced downstream of the burner flame front, residence time should also be calculated from the final air injection point [18].

\subsection{Assessment of Incinerator Performance in Tanzania}

The assessment of operational problems in the existing incinerator designs has been conducted at Muhimbili National Hospital (MNH), Medical Stores Department (MSD), Mwananyamala Hospital (all in Dar es Salaam), Mnazi Mmoja Hospital (MMH) in Zanzibar, and Bugando Medical Center (BMC) in Mwanza in 2004. Problems identified include low incinerator capacities $(\mathrm{kg}$ waste/h), high fuel consumption rate $(\mathrm{L} / \mathrm{h})$, poor combustion efficiencies, poor chamber designs, and air pollution problems [8]. However, none of the assessment studies concentrated on one unit to establish its performance based on long term behavior. This study concentrated on one unit for 22 months which is operated in a district hospital (Temeke).

\section{Materials and Methods}

\subsection{Design Features of the Assessed Incinerator}

The old Temeke hospital incinerator was a simple facility comprising of a cylindrical combustion chamber with an opening for waste feeding and a chimney for smoke outlet, as shown in Figure 1. The secondary burner is connected to the chimney, which acts as a secondary chamber. Such units are not suitable in terms of combustion efficiency and environmental acceptance. The first chamber performs pyrolytic destruction of the waste and final combustion of gases takes place in the secondary chamber. This incinerator was designed mainly for destroying placentas from labor wards, but due to scarcity of incineration facilities, it was used for destroying all medical waste generated in a district hospital.

The fuel consumption was alarmingly high, about 20 $40 \mathrm{~L} / \mathrm{h}$, which necessitates investigation. The maximum temperature was about $700^{\circ} \mathrm{C}$ only in the secondary chamber, but the primary chamber temperature was only about $400^{\circ} \mathrm{C}-500^{\circ} \mathrm{C}$. The incinerator had the capacity to burn only about 10 placentas per day, but was usually loaded from 60 to $120 \mathrm{~kg}$ of mixed medical waste due to lack of air pollution control device made the whole equipment less useful. Other waste types (like chemicals, 


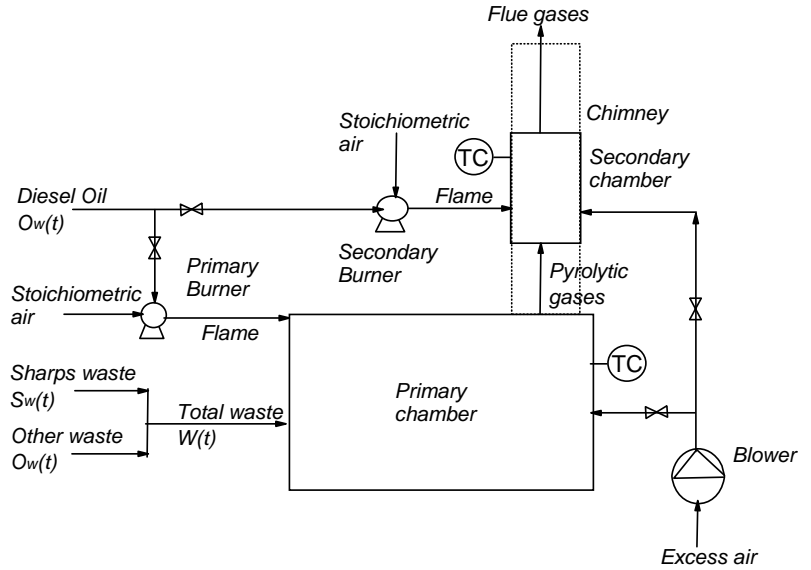

Figure 1. Design features of the assessed incinerator.

pharmaceuticals) could not be destroyed due to lack of air pollution control device (APCD). The incinerator was located in densely populated area, which made the smoke problem to be a continuous nuisance to the nearby community. Another incinerator problem in relation to its location was fluid leakage (blood) from the drying placentas in the primary chamber onto the floor which caused aesthetic view and odorous environment.

\subsection{Experimental Model Formulation}

Figure 1 shows the process flow sheet for the double chamber incinerator used in this study. In this model, the input parameters studied include: Sharps waste loaded in primary chamber, $S_{w}(t)$; Other waste loaded in primary chamber, $O_{w}(t)$; Total diesel oil consumed per cycle by the two burners, $D_{o}(t)$, and the incineration cycle time, $T_{c}(t)$, where $t$ denotes time in days. The quantity of air through the burners (stoichiometric air) and blower (excess air) were not determined. The time series recorded for $N=653$ days, can be expressed as per Equation (1), in which, each parameter was recorded separately:

$$
X_{i}(t)=\left\{\begin{array}{c}
S_{w}(t) \\
O_{w}(t) \\
D_{o}(t) \\
T_{c}(t)
\end{array}\right.
$$

The total weight of the waste loaded into the primary chamber, $W_{i}(t)$, was determined by adding the amounts of sharps waste and other waste as shown in Equation (2):

$$
W_{i}(t)=S_{w}(t)+O_{w}(t)
$$

\subsection{Data Collection Methods}

The data collection took about 22 months (653 days) from August 2007 to May 2009. The operators were trained on how to conduct the data recording exercise. Medical waste was segregated into different containers at the points of generation (plastic bags for other waste and safety boxes for sharps waste), collected for the whole day, weighed and recorded ( $\mathrm{kg} /$ day) ready for incineration. The checklist was designed to suit the type of data to be collected, in which the amounts of sharps waste loaded (kg/day), other waste loaded ( $\mathrm{kg} /$ day), diesel oil used (L/day) and incineration cycle time (h) were recorded. One incineration cycle was performed per day, such that $\mathrm{kg} /$ cycle or $\mathrm{kg} /$ day represents the same quantity.

\subsection{Time Series Analysis Techniques}

The total waste incinerated per day, $W_{i}$, was defined as the total weight of waste (both sharps and other waste, in $\mathrm{kg}$ ) loaded into the incinerator primary chamber per day (also called incineration rate). The average medical waste incinerated per day, $W$, for the whole period $(N=653$ days), was computed as per Equation (3):

$$
W=\frac{\sum W_{i}}{N}
$$

Moreover, the average values for $S_{w}(t), O_{w}(t), D_{o}(t)$ and $T_{c}(t)$ were determined using Equation (4):

$$
X=\frac{\sum X_{i}}{N}
$$

The range, $R$, (for the amount of waste incinerated, diesel oil used, or incineration cycle time), was determined from the difference between the maximum and minimum values. The standard deviation of (the waste incinerated per day, diesel oil used, incineration cycle time), $\sigma$, was also analyzed to quantify deviations in the measured parameters from their respective mean values. The probability density function (PDF) which reveals quantitatively the scatter of values of a time series from the mean value and gives a better overall picture of the temporal behavior in the process, were also used. To describe the asymmetric properties and peakedness of the probability density functions (PDFs), the skewness factor, $S_{k}$, and kurtosis, $K_{u}$, were used, respectively [19].

The skewness factor gives a measure of the degree of asymmetry of a PDF around its mean value. Higher positive skewness factor signifies a PDF with relatively longer tails towards right hand side while lower positive $S_{k}$ signifies PDF with shorter tails towards higher values of the data. Thus, higher positive $S_{k}$ shows strong variations in daily waste incineration data. Skewness factor was determined using Equation (5):

$$
S_{k}=\frac{1}{N_{1}} \sum_{i=1}^{N_{1}}\left[\frac{X_{i}-\overline{X_{i}}}{\sigma}\right]^{3}
$$


Kurtosis is a measure of the relative peakedness of a PDF compared to a normal distribution. Higher values of $K_{u}$ signify a peaky PDF than that of a normal distribution which shows that many values are concentrated near the mean indicating also a low variation in the respective incineration data. Lower value of $K_{u}$ signifies flatter PDF, indicating that many values are spread away from the mean, as a result of high variation in medical waste incineration data. A zero kurtosis implies a normal distribution. Kurtosis was determined using Equation (6):

$$
K_{u}=\frac{1}{N_{1}} \sum_{i=1}^{N_{1}}\left[\frac{X_{i}-\overline{X_{i}}}{\sigma}\right]^{4}-3
$$

The values of $R, \sigma, S_{k}$ and $K_{u}$ were computed automatically using SPSS Software. Being higher moments of the time series, the skewness and kurtosis are more sensitive to changes in the waste incineration data than range, standard deviation and the mean values [19-21].

The waste incineration data was also normalized in order to compare the time series data using PDF, skewness and kurtosis. Normalized values, $X_{n}$, ranged between 0 and 1, computed as per Equation (7):

$$
X_{n}=\frac{\left(X_{i}-X_{\min }\right)}{R}
$$

where $X_{n}=$ normalized value; $X_{i}=$ daily data (kg waste/ day, liters diesel oil/day or cycle time in hours); $X_{\min }=$ minimum value in the respective time series, and $R=$ range of the respective values.

\section{Results and Discussion}

\subsection{The Nature of Time Series for the Daily Incineration Data}

The analysis of trends in the daily medical waste incineration data revealed that sharps waste incinerated varied from 20 to $40 \mathrm{~kg} / \mathrm{day}$, while other waste varied from 60 to $100 \mathrm{~kg} /$ day, as shown in Figure 2. On the other hand, the diesel oil used varied from $20 \mathrm{~L} /$ day to 40 $\mathrm{L} /$ day and incineration cycle time varied from 2 to $4 \mathrm{hrs} /$ cycle. In general, the data falls in the stationary time series category, fluctuating about a constant mean value for all data recorded. Stronger fluctuations were observed in sharps and other waste data than fuel oil used and cycle times. This can be attributed to the fact that generation of such waste is influenced by several factors like number of patients attended, number and types of services offered in a district hospital, waste collection efficiency, waste segregation efficiency and inherent practices, etc., which vary strongly in a district hospital. The time series analysis is intended to assist district hospital managers in understanding variations in the daily incinerator perfor-

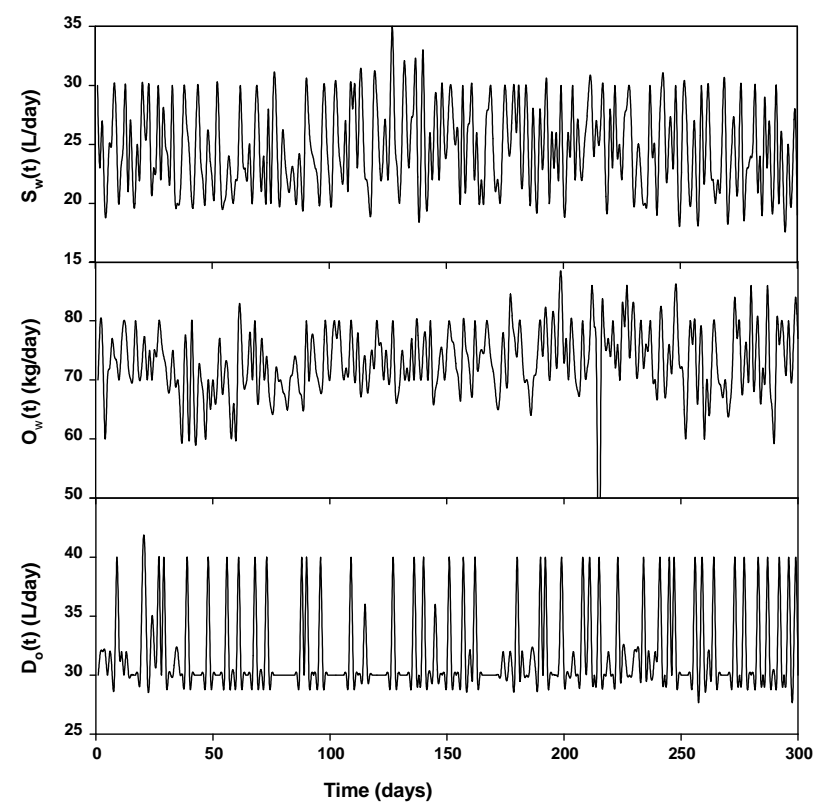

Figure 2. Sample time series for medical waste incinerator performance data (for $\boldsymbol{N}=\mathbf{3 0 0}$ days).

mance so as to accommodate them in the preparation of realistic and cost-effective plans and budget related to medical waste disposal.

\subsection{Average Values of Waste Incineration Data}

Based on the average values of daily incineration data it was observed that sharps waste incinerated were about $24.4 \mathrm{~kg} /$ day, other waste incinerated were about 73.5 $\mathrm{kg} / \mathrm{day}$, and the average diesel oil used was about 31.7 L/day while the average cycle time was observed to be $3.1 \mathrm{hrs}$ as shown in Figure 3. These result shows that, large quantities of sharps waste are incinerated per day in the health facilities. It was also observed that sharps wastes are properly and hygienically treated by incineration to ashes with assured sterilization and weight reduction. The use of 31.7 liters of diesel per day and $3.1 \mathrm{hrs}$ incineration cycle time indicates imperfect working condition of the incinerator. The fuel consumption is rather too high, indicating presence of non-combustible or wet materials, which lowers combustion temperature. The need for proper segregation of medical waste at the point of generation is thus inevitable.

The sharps waste incinerated were observed to be $25 \%$ while other waste were about $75 \%$ of the total waste as shown in Figure 3. These results indicate that, sharps waste incinerated was a quarter of the whole medical waste incinerated. This is large fraction which needs appropriate disposal technology to protect health workers, environment and the community. Thus, incineration was recommended for district hospitals due to large quantities of sharps waste generated as it suits several categories of 


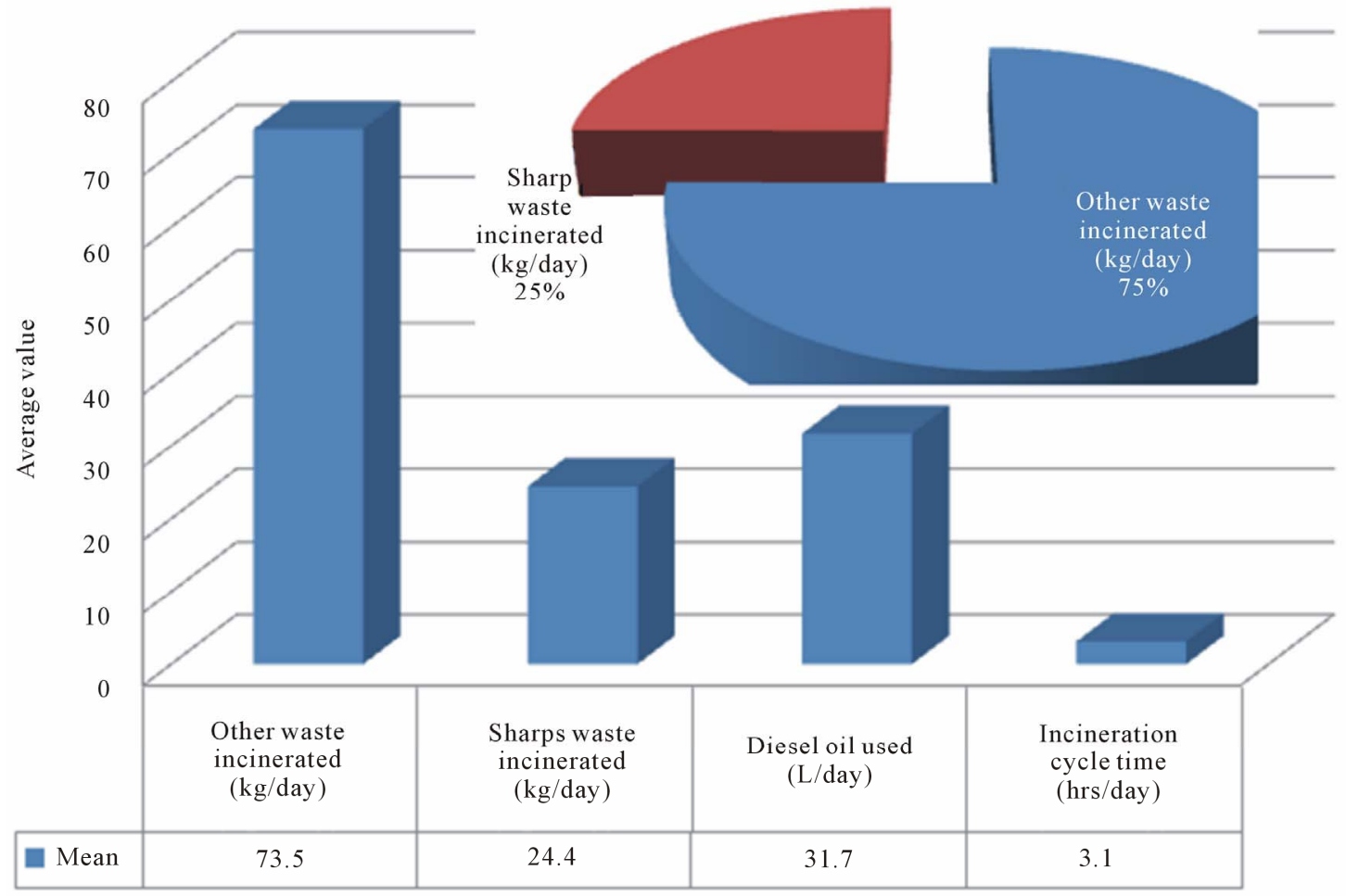

Figure 3. Average values of medical waste incineration parameters $(N=653)$.

waste at the same time. Further studies are required to assess the ash properties from incinerators destroying sharps waste in combination with other wastes.

\subsection{Frequency Distribution of Daily Diesel Oil Consumption}

The analysis of diesel oil used in relation to the amount of waste incinerated indicated that most of waste incinerated (about $74 \%$ ) used $30 \mathrm{~L}$ of fuel per cycle. A critical case was observed, whereby, about $18 \%$ of cycles used $40 \mathrm{~L} /$ cycle as shown in Figure 4. In few cases, 20 $\mathrm{L} /$ cycle and $32 \mathrm{~L} /$ cycle were used in $3 \%$ and $5 \%$ of cycles, respectively. The use of $40 \mathrm{~L} /$ day of diesel indicated very poor incinerator performance.

The detailed analysis to identify the actual reason for excessive fuel consumption, revealed that the days incinerator used excessive diesel were the rainy days which lead to wet waste with high moisture content. This was due to poorly designed waste storage bay, without roof and its sides not covered. It was recommended that the design and construction of incinerator should go together with standard waste storage bay to be able to accommodate weather variations and improve the incineration process. The use of large amount of diesel is likely to increase the running cost in the district hospital. As hospital resources are always scarce, this tendency may reduce management willingness in the technology choice and utilization.

\subsection{Frequency Distribution of Incineration Cycle Times}

The analysis of the incineration cycle times revealed that, most of the cycles (about 80\%) used 3 hours to achieve total destruction of the waste to the required standards. About $4 \%$ of cycles were observed to reach completion in about 2 hrs only while about $16 \%$ of cycles used 4 hours as shown in Figure 5. The shorter incineration cycle time corresponded to large proportions of sharps waste compared to other waste and also to dry waste loaded. Similarly, this observation correspond to low values of total waste $(\mathrm{kg} /$ day) incinerated.

The use of excessive long cycle time (4 hours) was also an indication of imperfect incineration process due to improper operation. The detail analysis revealed that, there was no proper sorting of waste at point of generation to eliminate the presence of incombustible materials such as pressurized containers and other wet waste materials which interfered with temperature in the combustion chamber. These results resembles the data reported by [5], where by proper operation of incinerators should achieve desired temperatures, residence times, and other conditions necessary to destroy pathogens, minimize emissions, avoid clinker formation and slugging of the ash (in the primary chamber), avoid refractory damage destruction, 


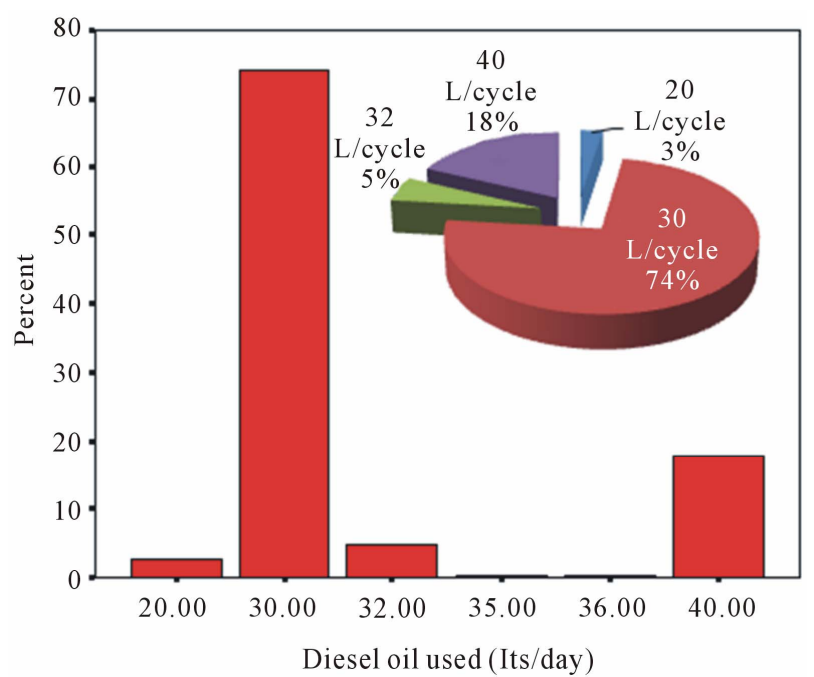

Figure 4. Frequency distribution of diesel oil consumption.

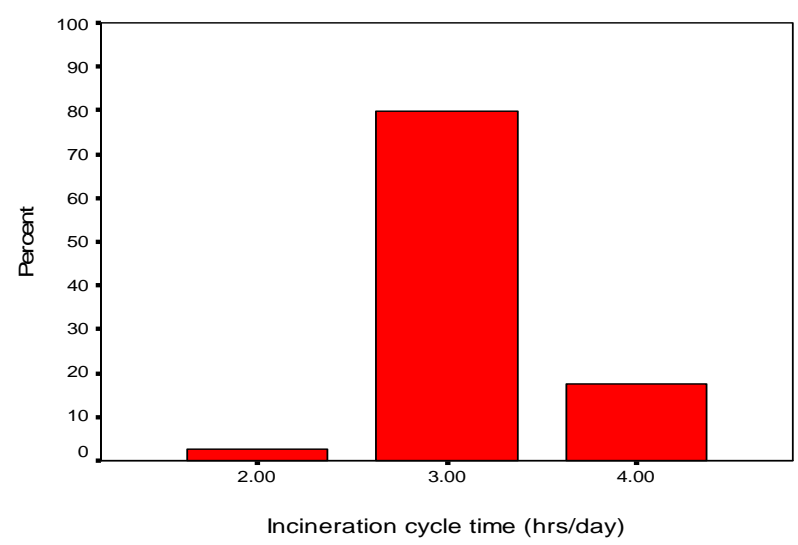

Figure 5. Frequency distribution of incineration cycle time.

and minimize fuel consumption.

\subsection{Measuring Variations in the Medical Waste Incineration Data Using Statistical Analysis}

\subsubsection{Measuring Spread in the Waste Incineration Data}

The range was studied to assess the fluctuations in the incineration data. The results showed that, sharps waste incinerated has a range of $23 \mathrm{~kg}$ and other waste had range of $42 \mathrm{~kg}$ as shown in Figure 6. The wide range in values can interfere with hospital plans and budget because it is difficult to predict the amount of waste to be incinerated each day. The results also observed the range of 20 liters for diesel oil used and $2 \mathrm{hrs}$ incineration cycle time. The range analysis necessitated the study of standard deviation in order to quantify the deviation from mean and magnitude of daily medical waste incineration variations.

The standard deviation was analyzed to quantify the average deviations from the mean value. The results showed that sharps waste incinerated deviated for about $3.9 \mathrm{~kg}$ of waste per day which indicates that most data point were closer to the mean, while other waste showed deviation of about $6.8 \mathrm{~kg}$ per day which is the indication of a wider spread of the data as shown in Figure 6. Similarly, wide variations in the $O_{w}$ data can be attributed to the fact that its generation is affected by many other factors compared to sharps waste which is collected in safety boxes in specific hospital areas. These results indicated the presence of wide variation in other waste than sharps waste due to the fact that other waste contained non-segregated waste with different levels of moisture content in some cases. Sharps waste is usually contained in safety boxes such that it remains unchanged prior to incineration. Hospital waste management plans and budgets should accommodate these variations.

The diesel oil used also showed deviation of about 4.3 $\mathrm{L} /$ day, which is an indication of weak variations in the data. To serve fuel, there is a need for district hospitals to properly segregate the waste at points of generation and put away the incombustible wastes from interfering with the combustion process. The standard deviation of cycle time was observed to be 0.4 , which indicates a minimal deviation, although the performance in terms of cycle time was out of control.

\subsubsection{Probability Density Functions for Incinerator Performance Data}

The study analyzed probability density function of the incineration data in order to quantify the spread in the daily incinerator performance data. High frequency distribution for sharps waste incinerated concentrated between 20 and $30 \mathrm{~kg} /$ day (with highest frequency at $25 \mathrm{~kg}$ sharps waste per day, similar to the results shown in Figure 2), which indicate that the average quantity of sharps waste incinerated in most of the days was about $25 \mathrm{~kg}$. On the other hand, the high frequency distribution for other waste incinerated was about $75 \mathrm{~kg}$ as shown in Figure 7.

The results also indicated that most of waste incinerated used about 30 liters of diesel oil in most of the days and the incineration process was more often completed in about 3 hrs. The incineration cycle time was, however, too long leading to higher fuel consumption. This necessitated change in the incineration technology.

Together with the values of $S_{w}$ ranging between 20 and $25 \mathrm{~kg} /$ day, in some cases higher values of 40,50 and sometimes $60 \mathrm{~kg} /$ day were observed, showing that sharps waste varies widely towards higher values. Meanwhile, higher values of $O_{w}$ up to $150 \mathrm{~kg} /$ day were also observed, but at a lower frequency. Based on the peaks in the PDFs and also on the fixed length of the time series, $N=653$, it is evident that $S_{w}$ shows strong variations (lower peaks, with highest frequency of $f \approx 300$ ) than $O_{w}$ (higher peak, 


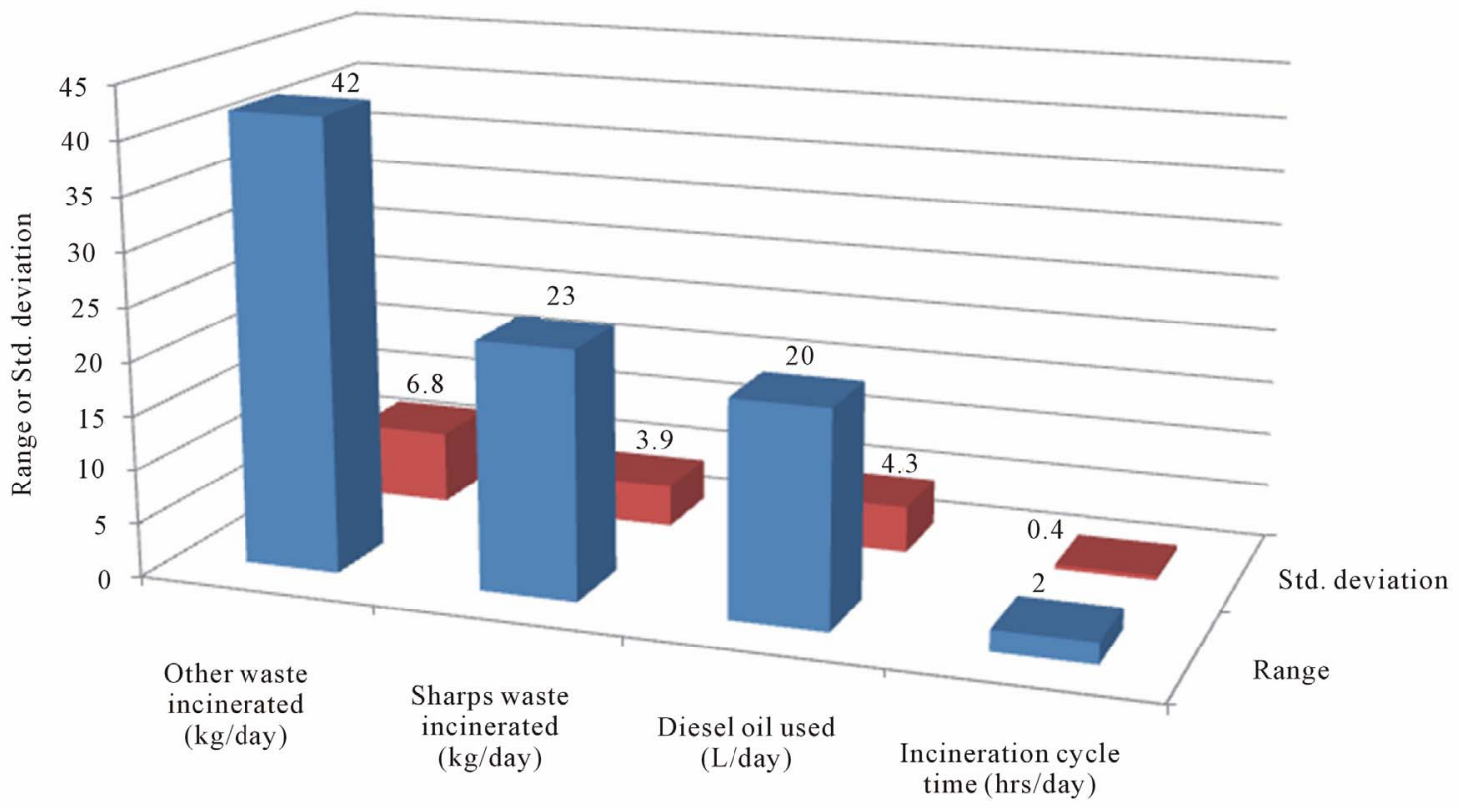

Figure 6. Range and standard deviation of waste incineration data.

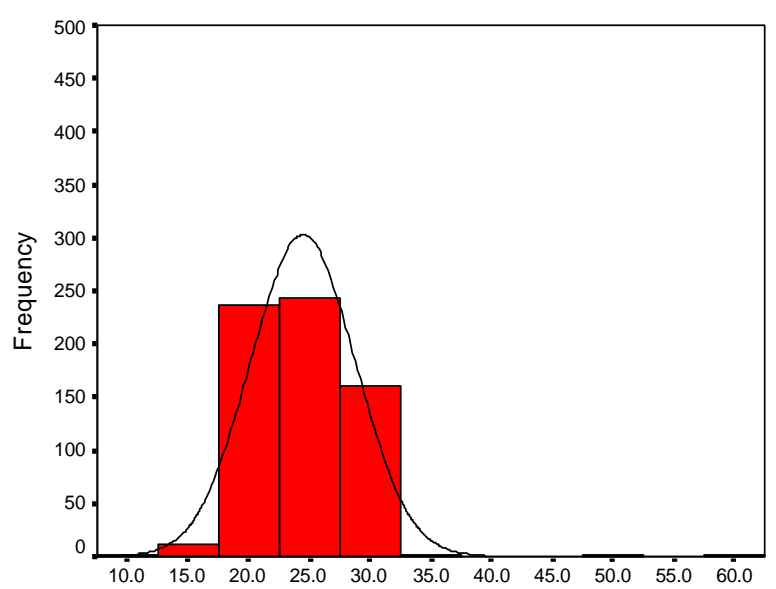

Sharps waste incinerated (kg/day)

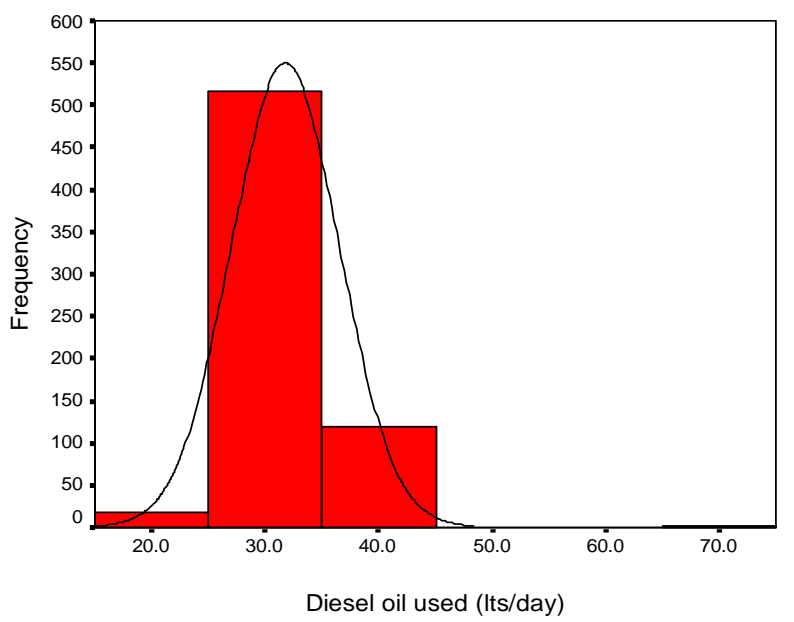

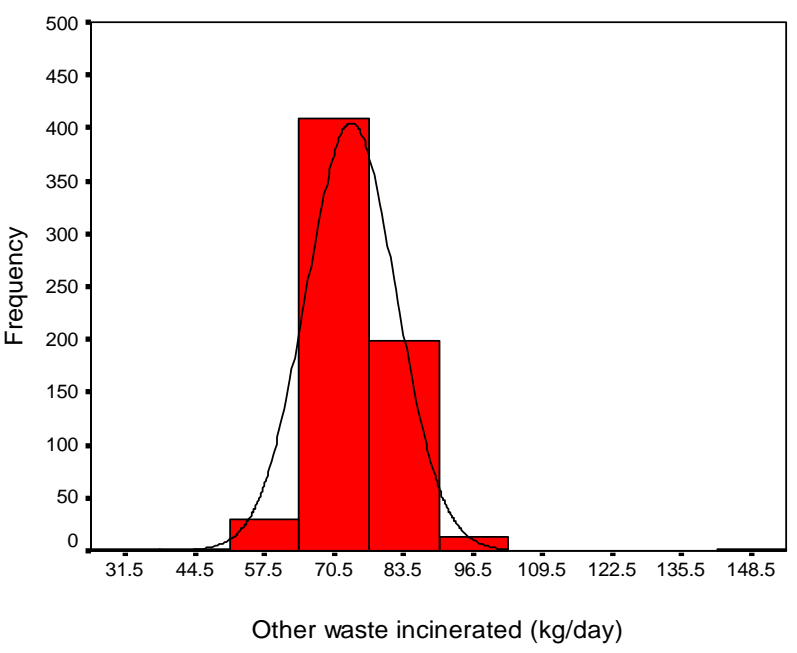

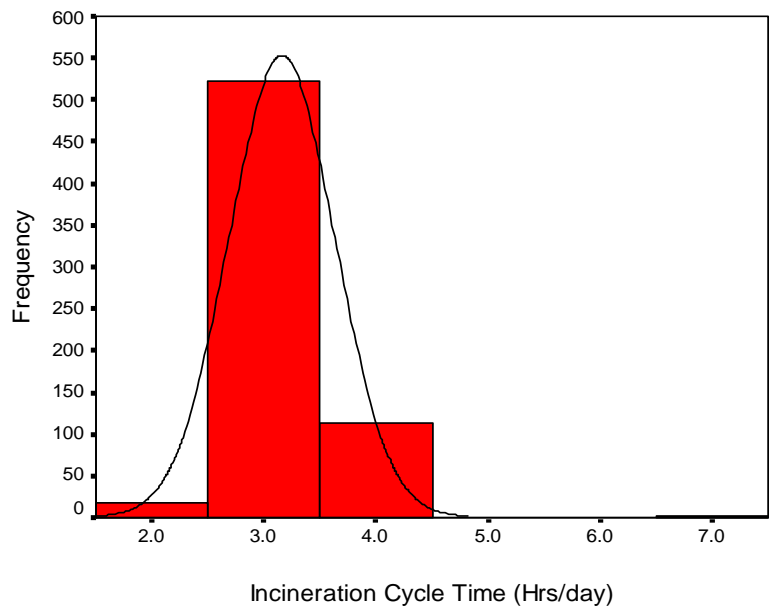

Figure 7. Probability density function of medical waste incineration data. 
with highest frequency of $f \approx 420$ ).

A high uniformity was observed in the daily fuel consumption and cycle time data $\left(D_{o}\right.$ and $T_{c}$, respectively), with highest frequency of about $f \approx 500$ or $76.5 \%$ in both cases. The incinerator performance was however generalized to be poor due to the high fuel consumption and excessively longer cycle time. These results provide a broad picture to hospitals on the choice and utilization of incineration technology, and can be the bases for hospitals in decision making, planning and budgeting to achieve efficiency and effectiveness in medical waste management.

\subsubsection{Skewness and Kurtosis of the Time Series Data}

The skewness and kurtosis of incinerator performance data was used to quantify shapes of the PDFs and quantifying their peaks and tails. The results showed positive skewness distributions in all parameters, indicating presence of a large fraction of higher values above the mean in the time series as shown in Figure 8. This can also be observed in Figure 5. The results also indicated weak variations for sharps waste compare to other waste in daily medical waste incineration data as stated earlier, also due to changes in the number of procedures conducted in a particular day and patient attendance (in and out patient).

Kurtosis was used to measure the peakedness and flatness of the PDFs of incineration process data as shown also in Figure 8. The result showed lower kurtosis values for sharps waste than other waste data indicating high variations in sharps waste incinerated, similar to results shown in Figure 7. According to Figure 8, strongest variations were observed in other waste than sharps waste. The values of $K_{u}$, however, were similar for $S_{w}, D_{o}$, and $T_{c}$.

\subsection{Statistical Analysis of Normalized Incinerator Performance Data}

\subsubsection{Probability Density Functions of Normalized Incinerator Performance Data}

The comparison of the daily incinerator performance data using the PDF shapes was difficult because of the wide differences in the range of values. For that reason it was necessary to normalize the data, whereby each time series was made to range between " 0 " and " 1 ". The normalized incinerator performance data were then properly analyzed as described below.

The analysis of the probability density functions of the normalized incinerator performance data indicated that, the high frequency distribution for $O_{w}$ was observed at $X_{n}$ $=0.5$ and 0.8 with the peak ranging between $15 \%$ and $20 \%$ while most of the values were spread away from the mean with low percent of about $5 \%$ for higher values indicating strong variations of other waste, as shown in Figure 9.

The normalized values of sharps waste incinerated per day, $S_{w}$, concentrated between $X_{n}=0.3$ and 0.9 , with most of the values distributed away from the mean between 5 and $15 \%$, which indicates weak variations in $S_{w}$ compared to other waste. The PDF of total waste incinerated carries the characteristics of both sharps and other waste for which most of values distributed away from the mean with low percent indicating high variations in the total medical waste incinerated on daily basis.

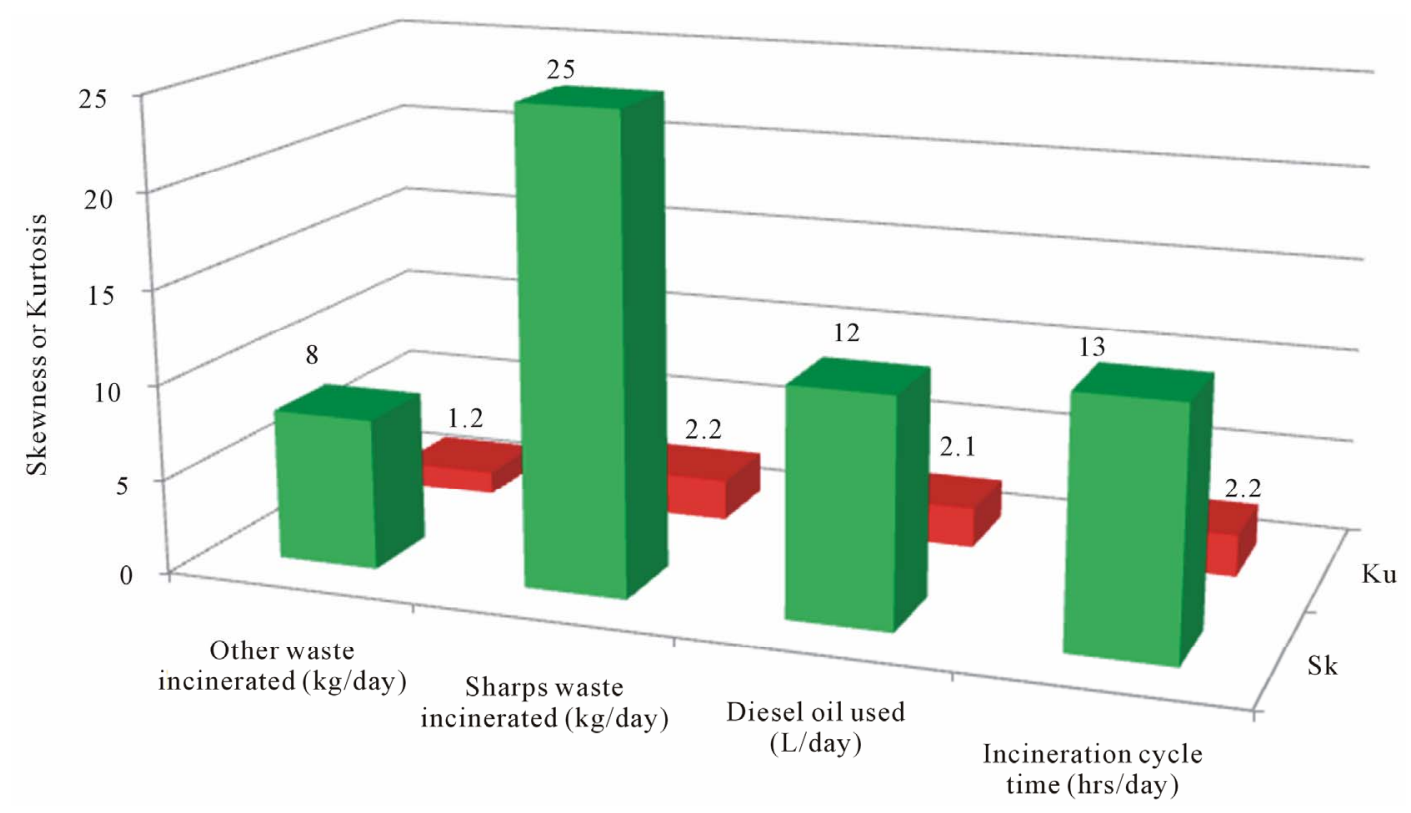

Figure 8. Skewness and kurtosis of incinerator performance data. 

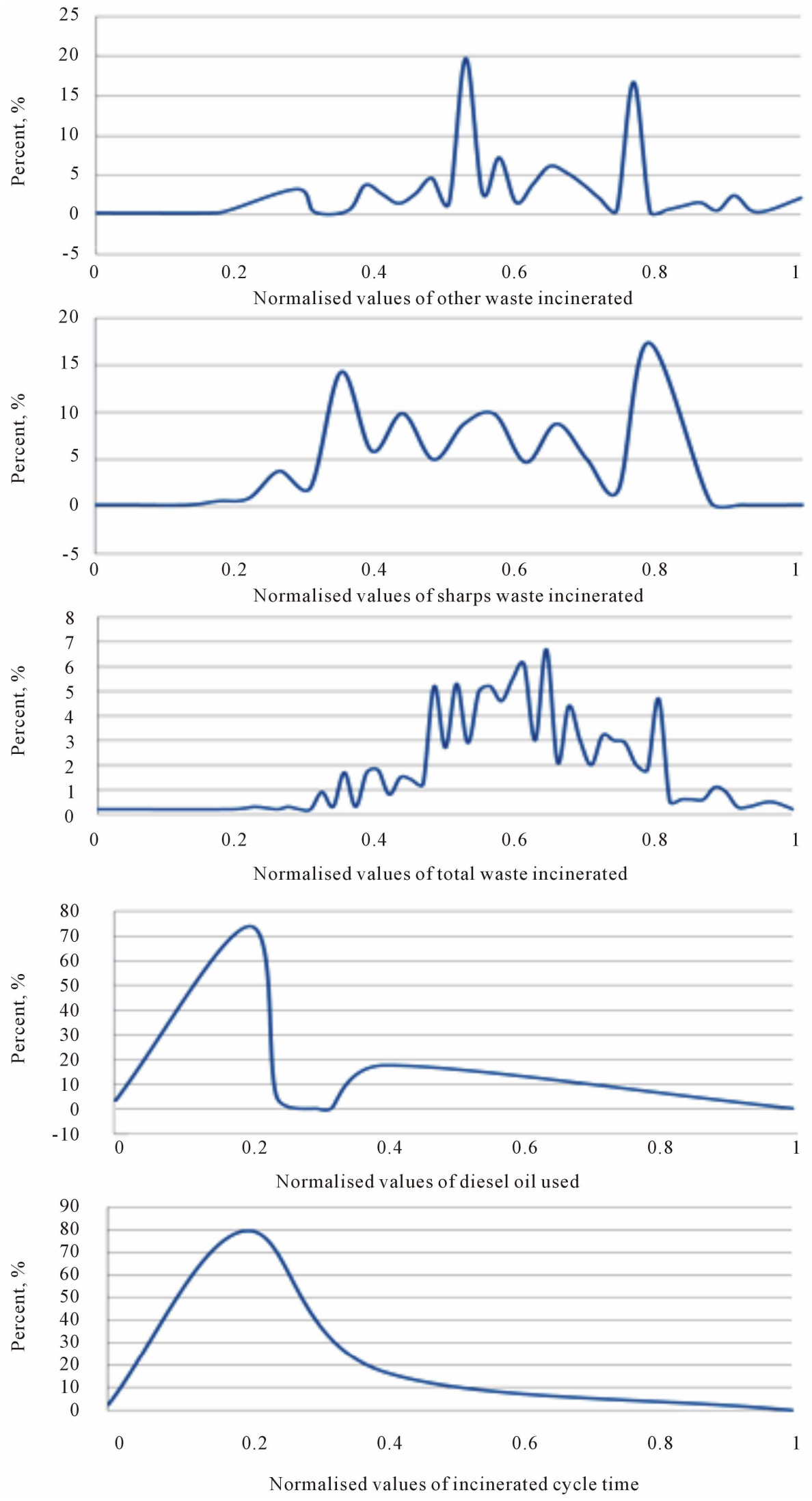

Figure 9. Probability density function of the normalized incinerator performance data. 
The diesel oil used showed high percent (74\%) at $X_{n}=$ 0.2 with long tail spreading away from the mean towards higher values which indicates high positive skewness despite of high uniformity. The PDF for diesel oil consumption per day indicated a bimodal behavior, the first higher peak at $X_{n}=0.2$ and a second shorter peak at $X_{n}=$ 0.4 . This is an indication of a system under the influence of more than two factors. The observed variation was due to poor segregation of waste from different hospital sections and wet waste during rainy season caused by poor design of the waste collection bay constructed without roof and side walls for protection of the waste against rain. All these factors lower the incinerator performance leading to high diesel oil consumption $\left(D_{o}\right)$, and extended incineration cycle time $\left(T_{c}\right)$.

The incineration cycle time showed high percent (80\%) at $X_{n}=0.2$ with long tail towards the higher values, which indicates high incineration cycle times at lower frequencies or positively skewed distribution. The observed high variation in cycle time also indicates imperfect performance of the incinerator.

The probability density functions of the daily incineration data were also studied by comparing all the PDFs of normalized data together. The results showed that, other waste incinerated have low percent but with high variations compared to sharps waste which had high percent in most of the values as shown in Figure 10. The fuel oil consumption and incineration cycle time's data indicated high uniform trend different from sharps, other waste and total waste incinerated per day. The data clustered between $X_{n}=0$ and 0.4 for cycle times and 0 to 0.25 for diesel oil used. The waste data were widely spread between $X_{n}=0.2$ and 0.9 , indicating strong variations in daily data. It is evident that the problems leading to lower incinerator performance in a district hospital are strongly related to poor medical waste management practices and to a weak extent depends on the performance of the incinerator accessories.

\subsubsection{Standard Deviation, Skewness and Kurtosis of the Normalized Data}

The standard deviation was analyzed to quantify deviations from the mean using normalized values. The results showed that the normalized values of $O_{w}$ have a standard deviation $\sigma_{n}=0.17$ normalized values of $S_{w}$ had a slightly lower value of $\sigma_{n}=0.16$. These results indicated the presence of stronger variation in other waste than sharps waste. However, both sharps and other waste showed significant deviations in daily waste incineration indicating unpredictable situation compared to diesel oil consumed and incineration cycle time. The diesel oil used and incineration cycle time revealed weak variations with $\sigma_{n}=0.09$ and 0.08, respectively, as shown in Figure 11.

The skewness was used to quantify the tails of PDFs to reveal the details of daily variations in medical waste incineration data using normalized values. The results showed negatively skewed distributions for other waste $\left(S_{k}=-0.1\right)$ and sharps waste $\left(S_{k}=-0.3\right)$ indicating existence of many lower values at a low frequency. This is evident from Figure 9, where long tails can be observed towards lower values for normalized $O_{w}$ and $S_{w}$ data. The total waste incinerated was skewed negatively as well showing distributions to be tailed on the left indicating high variation in lower values of total waste incinerated as shown in Figure 11. Results show higher positive skewness values for the $D_{o}$ and $T_{c}$ data, implying long tails towards higher values. This gives an indication of poor incinerator performance.

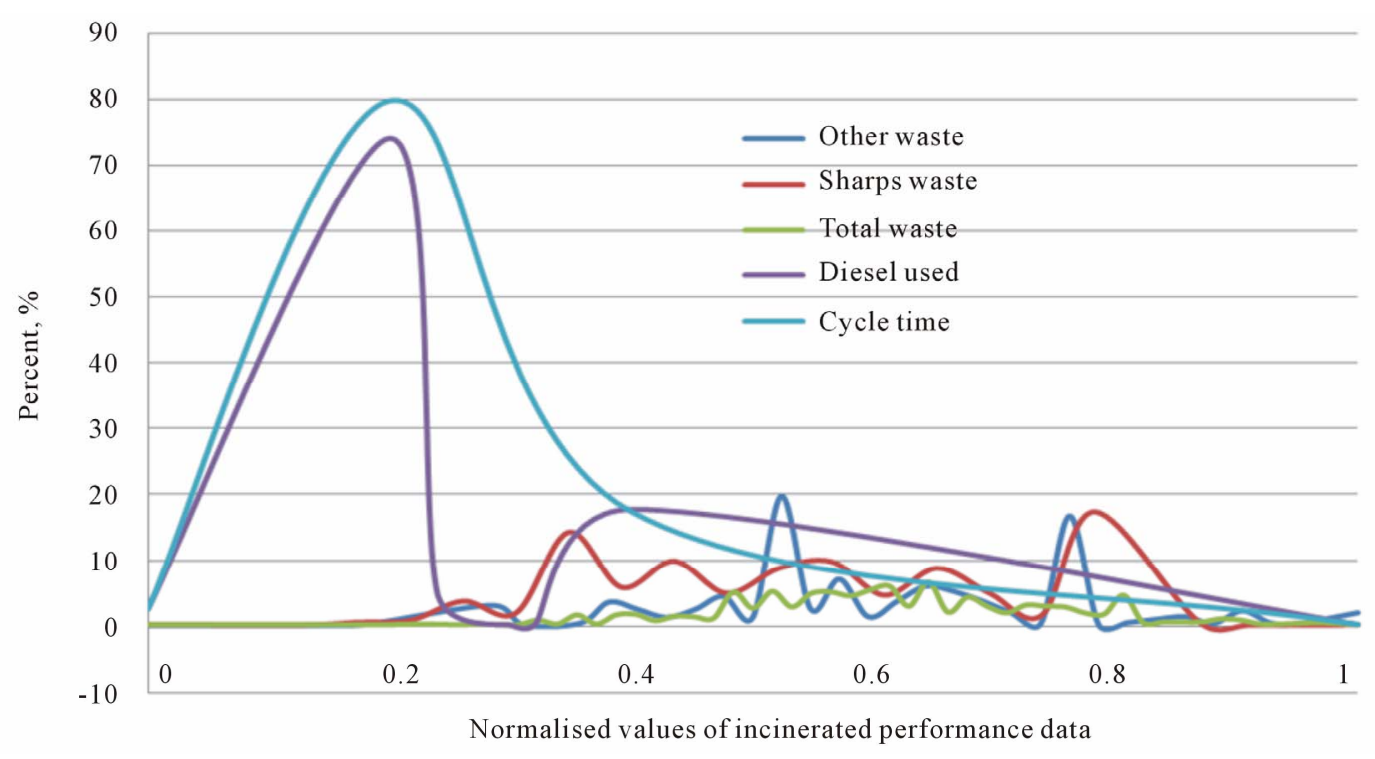

Figure 10. Probability density function of the normalized incinerator performance data studied in group. 

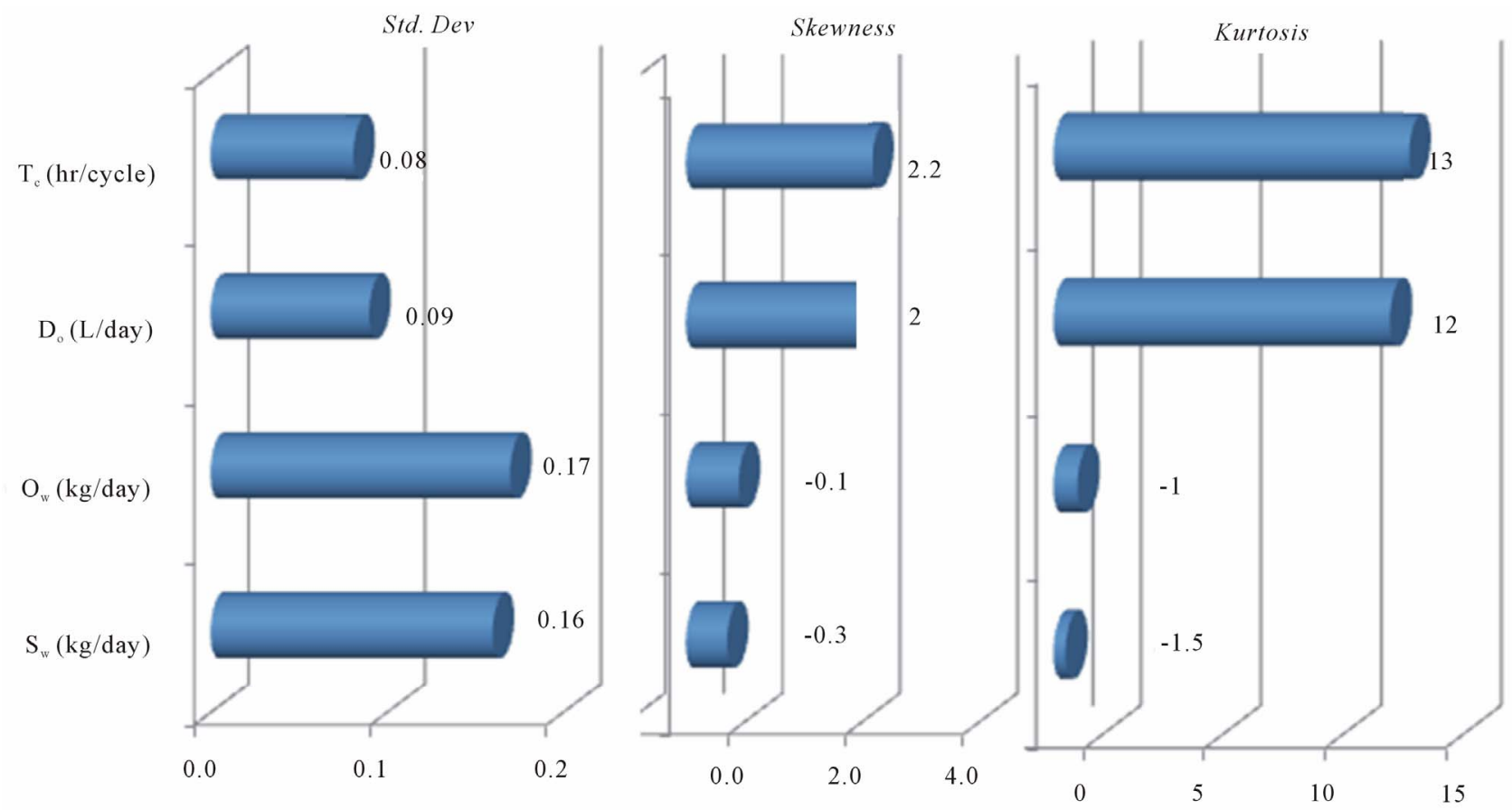

Figure 11. Standard deviation, skewness and kurtosis of the normalized incinerator performance data.

Kurtosis was used to measure the peakedness and flatness of the PDFs of the daily incinerator process performance data as shown in Figure 11. The result showed lower kurtosis values for $O_{w}$ and $S_{w}$ data, which implies flatter PDFs, and indicating high variations in the daily waste incinerated. The variation in waste incineration data was associated to inconsistence waste collection system in the district hospital sections, number of procedures conducted in a particular day and patient attendance (in and out patient) on that day. The $D_{o}$ and $T_{c}$ data exhibit high kurtosis values $\left(K_{u}=12\right.$ and 13, respectively), indicating high uniformity in the data. The results showed peaky distribution closer to the mean indicating weaker variations in diesel oil used and incineration cycle time. This can also be observed in Figures $\mathbf{9}$ and $\mathbf{1 0}$.

\subsubsection{Cumulative Functions of the Normalized Incinerator Performance Data}

Cumulative distribution functions were also utilized to compare the variations in the daily incineration data. The results showed that incineration cycle time and diesel oil consumption data had few values but with high cumulative percent reaching common model value (100) faster indicating low variations and high uniformity in the data as shown in Figure 12. Although fuel oil used and incineration cycle time showed low variation due to consistence in daily distributions, the actual diesel used and cycle time were excessively high.

Sharps waste and other waste data were observed to have strong variations taking a long way to reach the common model value as reflected also in the total waste. This indicated a strong variation in daily data for sharps and other waste incinerated compared to diesel oil consumed and cycle time. The total waste data accommodates the variations in both sharps and other waste.

\section{Conclusion}

This paper gives more insight to hospitals on the incineration process, and its major challenges. The study has established a database of information and statistics on medical waste incineration as part of medical waste management. Incineration data has been properly recorded and analyzed to have information's that will form the basis for realistic planning, designing and budgeting which is economical, effective and efficient. These results showed that sharps waste is quarter of the whole waste incinerated per day in Hospitals, which indicate the need of appropriate technology to be applied otherwise it may bring danger to human health and environment. The study analyzed the distribution of diesel oil used in relation to amount of waste incinerated, It was observed that, the use of large amount of diesel is likely to increase the running cost, which will then make the technology expensive. The assessment of incineration cycle time showed that, most of waste incinerated was totally destroyed within 3-hour time, which raise the need for proper segregation of waste at the point of generation as to eliminate the incombustible materials such as pressurized containers, glass, metals, and wet waste materials which 


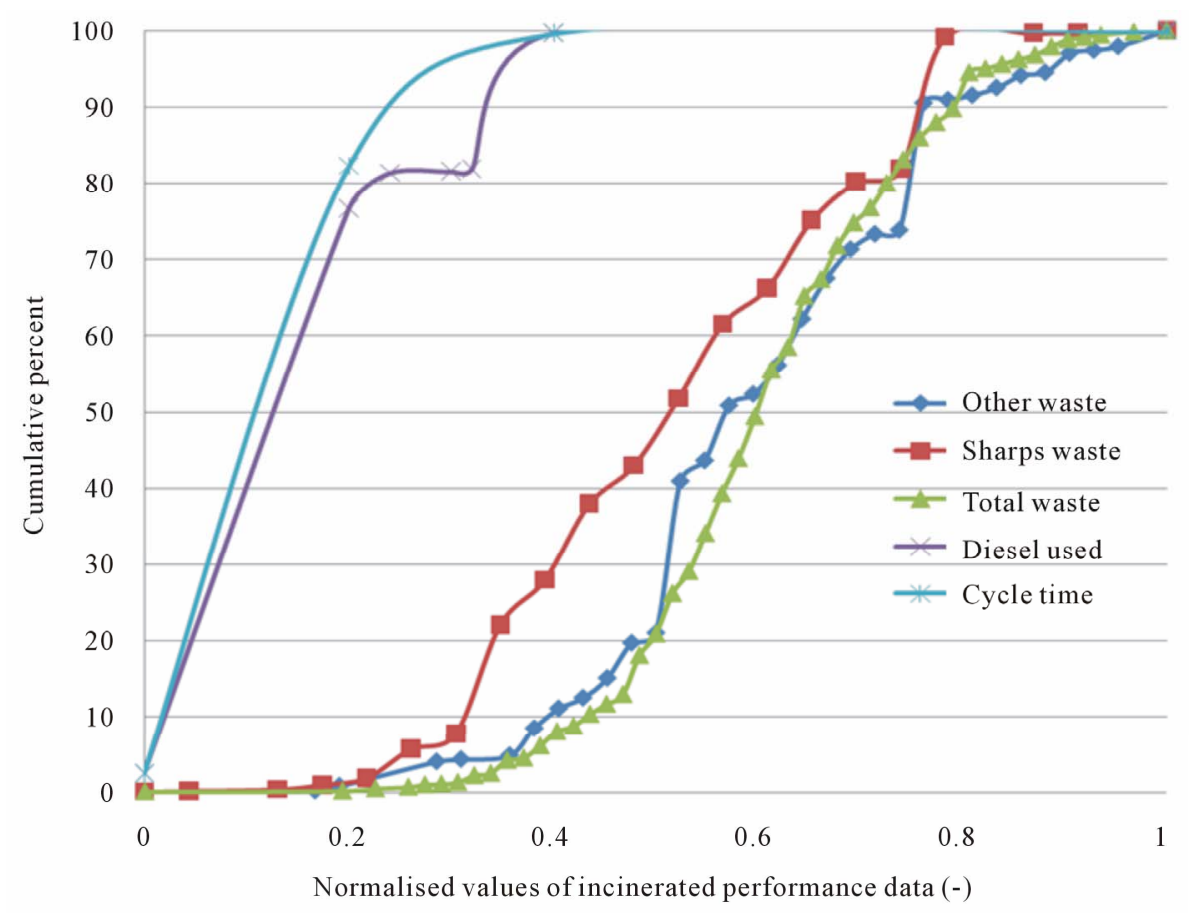

Figure 12. Cumulative functions of the normalized incinerator performance data.

interfere with temperature in the combustion chamber and increase the incineration cycle time. Proper segregation at point of generation and proper storage of medical waste was also recommended. It was further recommended for the hospital to install a new and efficient incinerator with short incineration cycle time and less fuel consumption.

\section{Acknowledgements}

The completion of this study has been the results of assistance received from Temeke Municipal Council health office in particular Temeke hospital medical officer in charge, Health Officer and the incinerator operator for their assistance in data collection.

\section{REFERENCES}

[1] S. V. Manyele and C. M. Mujuni, "Current Status of Sharps Waste Management in Lower Level Health Facilities in Tanzania," Tanzania Health Research Journal, Vol. 12, No. 4, 2010, pp. 257-264.

[2] Environmental Protection Agency (EPA), "Guide for Infectious Waste Management," Office of Solid Waste and Emergency Response, Washington DC, 1997.

[3] S. V. Manyele and T. J. Lyasenga, "Factors Affecting Medical Waste Management in the Lower-Level Health Facilities," African Journal of Environmental Science and Technology, Vol. 4, No. 5, 2008, pp. 304-318.

[4] F. Powell, "Air Pollutant Emissions from the Incineration of Hospital Wastes: The Alberta Experience," Journal of the Air Pollution Control Association, Vol. 37, No. 7, 1987, pp. 836-839.

[5] L. Brna and J. Kilgroe, "Hospital Incinerator Emissions, Risks and Permitting: A Case Study," The 80th Annual Meeting of Air Pollution Control Association, New York, 21-26 June 1989.

[6] S. V. Manyele, "Toxic Acid Gas Absorber Design Considerations for Air Pollution Control in Process Industries," Educational Research and Reviews, Vol. 3, No. 4, 2008, pp. 137-147.

[7] S. V. Manyele, H. Anicetus and M. H. Bilia, "Globalization and Its Effects on Medical Waste Management in Tanzania," Proceedings of IET Annual Conference and General Meeting, Arusha, 4-5 December 2003, pp. 76-92.

[8] S. V. Manyele, "Medical Waste Management in Tanzania: Current Situation and the Way Forward," African Journal of Environmental Assessment and Management, Vol. 8, No. 1, 2004, pp. 74-99.

[9] S. V. Manyele and H. Anicetus, "Management of Medical Waste in Tanzanian Hospitals," Tanzania Health Research Bulletin, Vol. 8, No. 3, 2006, pp. 177-182.

[10] W. A. Rutala, M. M. Stiegel and F. A. Sarubbi Jr., "Decontamination of Laboratory Microbiological Waste by Steam Sterilization," Applied and Environmental Microbiology, Vol. 43, No. 3, 1992, pp. 1311-1316.

[11] J. Yaukey, "Incinerator Critic Blasts Cornell Plan," Ithaca Journal, 18 September 1996.

[12] W. C. Blackman Jr., "Basic Hazardous Waste Management," 2nd Edition, Lewis Publishers, Boca Raton, 1996.

[13] L. Llyod, "Working Paper on Small-Scale Incineration," The East \& Southern Africa Healthcare Waste Manage- 
ment Meeting, Dar es Salaam, 9-11 June 2003.

[14] E. T. Oppelt "Incineration of Hazardous Waste-A Critical Review," Journal of the Air Pollution Control Association, Vol. 37, No. 5, 2007, pp. 558-586.

[15] J. J. Santoleri, "Design and Operating Problems of Hazardous Waste Incinerators," Environmental Progress, Vol. 4, No. 4, 2009, pp. 246-251. doi:10.1002/ep.670040408

[16] Citizens' Environmental Coalition, "Managing Medical Waste," CED, Albany, 1992.

[17] B. Colin, "Environmental Chemistry," W. H. Freeman \& Co. Publishers, New York, 1998, pp. 215-382.

[18] W. Taylor, "Incinerator Operations and Maintenance," The International Symposium on Incineration of Indus- trial and Hazardous Wastes, Washington DC, 5 May 2003.

[19] R. A. Groeneveld and G. Meeden, "Measuring Skewness and Kurtosis," The Statistician, Vol. 33, No. 4, 1984, pp. 391-399. doi: $10.2307 / 2987742$

[20] D. N. Joanes and C. A. Gill, "Comparing Measures of Sample Skewness and Kurtosis," Journal of the Royal Statistical Society (Series D): The Statistician, Vol. 47, No. 1, 1998, pp. 183-189. doi:10.1111/1467-9884.00122

[21] S. V. Manyele, J. Zhu and H. Zhang, "Analysis of the Microscopic Flow Structure of a CFB Downer Reactor Using Solids Concentration Signals," International Journal of Chemical Reactor Engineering, Vol. 1, No. 1, 2003, pp. 1-17. doi:10.2202/1542-6580.1108 